Cuadernos de Historia Contemporánea

ISSN: 0214-400X

http://dx.doi.org/10.5209/chco.71906

\title{
Contrabandistas de ganado y redes de evasión en Navarra durante la guerra civil española
}

\author{
Fernando Mikelarena Peña ${ }^{1}$
}

Recibido: 31 de agosto de 2017 / Aceptado: 11 diciembre 2019

Resumen. Se analizan las características de las tres redes de evasión más importantes que operaron en Navarra durante la guerra civil. De ellas, solamente una, la Red Álava, era parcialmente conocida. Las fuentes empleadas han sido: la prensa; los registros de la Prisión de Pamplona; los expedientes de la Delegación de Hacienda, del Tribunal de Responsabilidades Políticas y de los Tribunales Militares; y entrevistas de los años setenta. Se muestra que los impulsores de las redes eran los contrabandistas de ganado más destacados antes de julio de 1936. Tras esa fecha ampliaron sus negocios al blanqueo de dinero y a la evasión de izquierdistas y nacionalistas, contando con la connivencia y la participación de sectores de las nuevas autoridades.

Palabras clave: Navarra; Guerra Civil; Redes de evasión; Contrabandistas de ganado.

\section{[en] Cattle smugglers and evasion networks in Navarre during the spanish civil war}

\begin{abstract}
The following article analyses and discusses the three most crucial evasion networks set up in Navarre during the Spanish Civil War. Among all those networks, only the system set it Alava was partially well-known. The sources used for writing this article are the following: Newspapers, Pamplona's penitentiary center's records, documents from the provincial offices of the State Agency for Tax Administration, and from what is known as "Tribunal de Responsabilidades Políticas y de los Tribunales Militares," and various interviews from the seventies. The article shows that the prime movers of those evasion networks before July of 1936 were cattle smugglers. After 1936 those smugglers expanded their businesses to money laundering and the evasion of left-leanings and nationalists. Those activities were carried out with the help and connivance of the new authorities of the period.
\end{abstract}

Keywords: Navarre; Civil War; Evasion network; Cattle smugglers.

Sumario. 1. Introducción. 2. El contrabando de ganado en Navarra. 3. Los Hermanos Erviti Cilveti. 4. La ampliación del negocio: los billetes estampillados. 5. La desarticulación de la red de evasión organizada por Martín Erviti Cilveti en febrero de 1938. 6. La red de Guillermo Frías Arizaleta. 7. La Red Álava y sus antecedentes. 8. A modo de conclusión.

Cómo citar: Mikelarena Peña, F. (2020). Contrabandistas de ganado y redes de evasión en Navarra durante la guerra civil española. Cuadernos de Historia Contemporánea, Vol. 42: 263-283.

ORCID: 0000-0002-4096-6470, Dpto. CC. de la Documentación e Historia de la Ciencia de la Universidad de Zaragoza

E-mail: fmikelar@unizar.es 


\section{Introducción}

En este artículo analizamos las tres redes estructuradas de evasión que funcionaron en Navarra durante la Guerra Civil y que permitieron la fuga de cientos de simpatizantes izquierdistas y nacionalistas ${ }^{2}$. Como es sabido, en Navarra triunfó el golpe de estado de junio de 1936 desde el primer momento y constituyó siempre espacio de retaguardia franquista. Como se verá, en estas redes participaron, de forma evidente o encubierta, los contrabandistas de ganado tradicionales que operaban en los valles de Ultzama y de Baztán, conformándose así una realidad poliédrica y mucho más compleja que lo que se podría pensar en un principio. De las tres redes reconstruidas, una de ellas, la Red Álava, era ya conocida, si bien hemos podido entrever que existió una red antecedente de la misma que funcionó con anterioridad a su fecha oficial de inicio, desde el verano de 1936, corroborándose, además, que en ella también tomaron parte contrabandistas de ganado. A escala comparativa y limitándonos estrictamente al periodo 1936-1939, la participación de contrabandistas tradicionales en redes de evasión durante la guerra civil hasta ahora había sido corroborada en Galicia ${ }^{3}$ y en Cataluña, aunque en este último caso para posibilitar la evasión de derechistas ${ }^{4}$.

Hemos podido recabar datos sobre las dos redes desconocidas mediante dos vías. Por un lado, mediante la consulta sistemática de los expedientes incoados por el Tribunal de Responsabilidades Políticas que se conservan en el Archivo Real y General de Navarra (ARGN) ${ }^{5}$. Por otro, a través de la búsqueda de posibles sumarios militares en el Archivo de la Comandancia Militar de Pamplona relativos a las personas encarceladas en la Prisión Provincial, según los estadillos que se conservan en el ARGN entre julio de 1936 y diciembre de $1940^{6}$, que, por sus apellidos, hemos estimado que serían procedentes de los valles fronterizos de los valles cantábricos y meridionales de Navarra. No obstante, con toda seguridad esas redes no fueron las únicas: habrían existido otras, autónomas o dependientes de las anteriores, que no hemos podido detectar al no haber sido detenido nadie por trabajar en ellas. Asimismo, es más que probable que en las redes reconstruidas hubiera operado más gente que nunca fue detenida. No nos detenemos en los casos de personas detenidas por haber pasado a gente por la frontera pero de las que no se ha podido inferir que trabajaban en red consolidada, aún cuando hemos localizado también varios ejemplos de ello.

2 Queremos subrayar que solamente nos fijamos en las redes que operaron durante la guerra civil, dejando de lado las que operaron después, así como la bibliografía que ha tratado de ellas.

3 Prada Rodriguez, Julio: "Fuxidos, entobados, desertores e contrabandistas. Aproximación á problemática das orixes da resistencia antifranquista en Ourense", Minius, 14 (2006), pp. 221-238.

4 Sánchez Agustí, Ferrán: Espías, contrabando, maquis y evasión. La Segunda Guerra Mundial en los Pirineos, Lleida, Ediciones Milenio, 2003. En este libro se analizan las redes de evasión de derechistas en Cataluña durante la Guerra Civil, pero sobre todo las redes existentes en Aragón y Cataluña tras 1940. Sobre Navarra se habla de la Red Comète ya en la Segunda Guerra Mundial. Asimismo, también para Cataluña y para el mismo tipo de redes, Piferrer, Jordi: El pas dels Pirineus: Les rutes d'evasió cap a Andorra i l'aventura de sant Josep Maria Escrivà de Balaguer a la tardor de 1937, Lleida, Pagés editors, 2009.

5 Archivo Real y General de Navarra (ARGN), Audiencia Territorial de Navarra, Tribunal Regional de Responsabilidades Políticas de Navarra.

6 ARGN, Diputación Foral y Provincial de Navarra, Servicios Gestionados por Diputación, Cárceles. 


\section{El contrabando de ganado en Navarra}

El contrabando de ganado en Navarra con anterioridad a la guerra civil no ha sido investigado hasta ahora. A pesar de las ricas informaciones que proporcionaba Félix Urabayen en su novela Centauros del Pirineo (Madrid, Espasa, 1928), con trasuntos literarios de personales reales, los escasos trabajos existentes sobre la actividad contrabandística en dicha provincia desde la historia y la antropología se han fijado exclusivamente en los paqueteros que pasaban los bultos y las cabezas de ganado en los años cuarenta y cincuenta del siglo XX cuando dicha práctica fue un elemento fundamental de captación de ingresos complementarios para el campesinado de los valles fronterizos ${ }^{7}$. Nada se ha dicho, por tanto, de los que se situaban en las cúpulas de las redes en las décadas anteriores.

Existentes ya con anterioridad, las redes de contrabando de ganado que operaban en Navarra registraron un fuerte impulso durante la primera guerra mundial a causa de las necesidades de caballos y mulas por parte del ejército francés. La prensa de esos años recoge cientos de aprehensiones, una parte del ganado exportado de forma ilegal. Lamentablemente, los expedientes de contrabando de aquella época, presentes en el Archivo General de Navarra y procedentes de la Delegación Provincial de Hacienda, se han perdido, comenzando la serie en 1924. Con todo, a partir de la consulta de los expedientes de contrabando del periodo 1924-1940 se comprueba, como se verá, la presencia en ellos de las redes de contrabandistas de ganado más importantes existentes entonces y que se corresponden con las surgidas en la época de la Gran Guerra. Y que, como veremos, durante la guerra civil o en los meses anteriores se adaptarán a otros fines como paso clandestino de personas de izquierda o nacionalistas, contrabando de armas o documentos, contrabando de billetes estampillados.

Frente al silencio del resto de la prensa, el periódico nacionalista $\mathrm{La} \mathrm{Voz} \mathrm{de} \mathrm{Na}$ varra fue el único que denunció, sin resultado, la existencia de dichas redes, dando clara idea de su magnitud. El 24 de junio de 1934 un artículo firmado por Un ganadero, denunciaba la impunidad estructural con la que funcionaba dicho tráfico ilegal, cuya dimensión se tildaba de escandalosa, por cuanto los contrabandistas podían alegar documentación acreditativa falsa incluso en el caso de aprehensiones. El 23 de diciembre de 1934 un artículo firmado por Martin Amigot Sesma, presidente de la Asociación de Ganaderos de Navarra, hablaba de "las miles de cabezas de ganado" que se exportaban ilegalmente con la mayor impunidad, resultando las guías de circulación ser papel mojado. El 30 de octubre de 1935 alguien bajo el seudónimo Aitzkor denunciaba "el elevadísimo número de vacas que diariamente pasan la frontera, y que para mayor vergüenza son transportadas en camiones por delante de los cuarteles de carabineros" y señalaba que las medidas burocráticas no servían de nada.

Esas denuncias venían a ratificar lo que apuntaban los procedimientos judiciales incoados por el Juzgado de Primera Instancia de Pamplona o los expedientes tramitados por la Junta Administrativa de Hacienda. El combate contra el contrabando estaba dificultado por las complicaciones objetivas para la persecución del delito en

\footnotetext{
Ortega Noguera, Rebeca y Zabalza Gárate, Gemma: "Navarra, tierra de contrabandistas: una aproximación histórica (guerra civil y posguerra)", Gerónimo de Uztáriz, 16 (2000), pp. 9-32; Perales Díaz, José Antonio: Fronteras y contrabando en el Pirineo Occidental, Pamplona, Gobierno de Navarra, 2004; Rosa Arburua, Gau lana. Kontrabandoa Bidasoa aldean, Irun, Alberdania, 2011.
} 
un territorio fronterizo amplio y montañoso y con abundantes zonas de paso. Pero también porque las pocas personas situadas al frente de dichas redes de contrabando de ganado gozaban de una gran impunidad por los apoyos que encontraban en las autoridades judiciales y gubernativas, así como en los diferentes cuerpos policiales. Los logros de estos rara vez fueron más allá del decomiso de las mercancías prontamente abandonadas por los paqueteros al menor atisbo de ser atrapados y casi nunca se sustanciaron en alguna detención in fraganti.

\section{Los Hermanos Erviti Cilveti}

Como se verá, la principal red de evasión de izquierdistas que operó en Navarra durante la guerra civil fue gestionada por los hermanos Erviti Cilveti, que eran, junto con su cuñado Fermín Iñarrea, los principales contrabandistas de ganado en Ultzama y Baztán y para quienes trabajaban otros contrabandistas de menor nivel.

Los hermanos Erviti Cilveti eran cuatro (Pedro, Martín, Ignacio y Evaristo) y eran naturales de Alkotz en el valle de Ultzama donde habían nacido a finales del siglo XIX y principios del XX. En nuestro repaso de los expedientes de contrabando incoados por la Delegación Provincial de Hacienda entre 1924 y 1939 los hermanos Erviti aparecen en múltiples ocasiones, figurando como los más denunciados ${ }^{8}$. Un Informe de febrero de 1939, presente en el expediente incoado por el Tribunal de Responsabilidades Políticas del primero de ellos, aseguraba que tenían "un amplio historial" de contrabandistas de ganado "en alta escala", estimándose que pasaban "cuatro o cinco mil cabezas de ganado vacuno anuales". Pedro Erviti, el de más edad, actuaba de administrador de los bienes del clan, y de "jefe de todos ellos", adquiriendo en la primavera de 1937 el Hotel España ${ }^{10}$, ubicado en Pamplona en la Plaza del Castillo y antes conocido como Hotel Quintana. Mientras Pedro y Martín residían en la capital navarra o en su pueblo natal, Ignacio y Evaristo residían en la localidad baztanesa de Elbetea, "con objeto de estar próximos a la frontera" aprovecharse de las ordenanzas baztanesas sobre pastos y de las facerías con otros ayuntamientos navarros o vascofranceses inscribiendo en el Registro especial de ganados reses con las que luego traficaban con guías falseadas ${ }^{12}$.

Además de los contrabandistas anteriormente mencionados, también hay que citar a los hermanos Galarregui Echenique (Agustín, Antonio, Juan y Pedro Máximo), originarios del caserío Eskisaroi de Lekaroz, de quienes el expediente formado por el Tribunal de Responsabilidades políticas a Pedro Erviti afirma que eran estrechos colaboradores suyos y de sus hermanos en el valle de Baztán y con quienes aparecen involucrados en los mismos asuntos en diversos expedientes de contrabando ${ }^{13}$.

8 ARGN, Delegación de Hacienda de Navarra, Tribunal de Contrabando, Expedientes 1927, 26; 1930, 9; 1931, $27 ; 1931,56 ; 1934,29 ; 1934,96 ; 1935,7 ; 1935,10 ; 1935,28 ; 1935,123-124 ; 1936,6$.

9 ARGN, Audiencia Territorial de Navarra, Tribunal Regional de Responsabilidades Políticas de Navarra, Expedientes de Responsabilidades Políticas, Rollo 425.

10 Ibid.

11 Ibid.

12 Archivo de la Comandancia Militar de Pamplona (ACMP), Sumarísimo 2364/1938. Esa forma de actuación también se denunciaba en ARGN, Delegación de Hacienda de Navarra, Tribunal de Contrabando, Expedientes 1934, 29; 1934, 46; 1935, 10; y 1935, 28.

13 ARGN, Delegación de Hacienda de Navarra, Tribunal de Contrabando, 1935, 113; 1936, 27; 1936; 32; 1936, $41 ; 1936 ; 52$. 
Los hermanos Erviti estuvieron ubicados en el republicanismo de izquierdas durante el periodo republicano, con toda probabilidad para beneficiarse del amparo gubernativo y policial, pero a la vez colaboraron con requetés y falangistas con anterioridad al golpe de estado pasando armas por la frontera para así asegurarse su apoyo en el caso de que llegaran a triunfar.

Un Informe de la Comandancia de la Guardia Civil de julio de 1937 aseguraba que Pedro Erviti era un significado izquierdista, pero que había pasado "armas de contrabando antes de haberse iniciado el Glorioso Movimiento nacional". La sección de Investigación de la Delegación Provincial de FET y JONS en Navarra sostuvo que había estado afiliado a Izquierda Republicana y que había apoyado en febrero de 1936 al Frente Popular "comprando votos públicamente"14. De Ignacio y Evaristo Erviti, residentes, en Baztán, se predicaban sus afinidades con elementos izquierdistas del valle como Blas Marín Fernández, exalcalde republicano de dicho valle. Ignacio y Evaristo habrían huído a Francia en noviembre de 1936, estableciéndose con Marín en Alduides, al lado de la raya fronteriza ${ }^{15}$. Se ha afirmado que Blas Marín y Evaristo Erviti fueron agentes del servicio secreto republicano en el País Vasco francés ${ }^{16}$.

El republicanismo de los Erviti podía responder a la necesidad de proteger su negocio con redes políticas. Un informe presente en el expediente de responsabilidades de Pedro Erviti indicaba que era "notorio el amparo que experimentaban" por parte de los dirigentes republicanos, con lo que aseguraban el éxito del $99 \%$ de las operaciones de paso clandestino de ganado ${ }^{17}$. De hecho, en los expedientes por delitos de contrabando que se les incoaron siempre salieron bien librados.

La implicación de los Erviti con el suministro de armas a los golpistas en los meses anteriores al 18 de julio a requetés y falangistas fue corroborada por requetés y falangistas señalados como Alejandro Utrilla, Eusebio del Burgo, Atanasio Zabalza Gorena y Francisco Barragán, así como por el propio Pedro Erviti ${ }^{18}$. En los expedientes de responsabilidades políticas incoados a los demás hermanos Erviti también se dijo de ellos que habían colaborado con Falange en asuntos de contrabando de $\operatorname{armas}^{19}$.

\section{La ampliación del negocio: los billetes estampillados}

El contexto de la guerra civil permitió a los hermanos Erviti Cilveti incorporar nuevos nichos de negocio. Uno de ellos fue el del contrabando de divisas mediante los billetes estampillados. Otro, el de la evasión de izquierdistas hacia Francia.

El estampillado de billetes surge el 7 noviembre de 1936 con la instauración por parte de los sublevados de un Banco de España con sede en Burgos y con la puesta

14 ARGN, Audiencia Territorial de Navarra, Tribunal Regional de Responsabilidades Políticas de Navarra, Expedientes de Responsabilidades Políticas, Rollo 425.

15 Ibid.

16 Barruso Barés, Pedro: "El servicio secreto republicano en el Sudoeste de Francia (1936-1939)", Cuadernos Republicanos, 49 (2002).

17 ARGN, Audiencia Territorial de Navarra, Tribunal Regional de Responsabilidades Políticas de Navarra, Expedientes de Responsabilidades Políticas, Rollo 425.

18 Ibid.

19 ARGN, Audiencia Territorial de Navarra, Tribunal Regional de Responsabilidades Políticas de Navarra, Expedientes de Responsabilidades Políticas, Rollos 379, 380 y 381. 
en circulación, desde el 12 del mismo mes, de un sucedáneo de moneda propia conformado por los billetes que originalmente habían sido emitidos por la República con anterioridad al 18 de julio a los que se añadía una distinción formal: un sello con dos círculos concéntricos y una inscripción. A la vez, se declaraban nulos los billetes puestos en circulación por la República después del 18 de julio de 1936. Mediante el estampillado de billetes el gobierno de Burgos perseguía conseguir una bandera de soberanía diferenciada, organizar un sistema monetario propio y destruir el sistema monetario republicano. La invalidación de todo billete que no llevara una estampilla que lo legitimara exigía el estampillado de los mismos en las sucursales del Banco de España, banca privada o cajas de ahorros. El efecto de la progresiva conquista de territorios fue la enorme revalorización de la peseta de Burgos en comparación con la peseta sin estampillar republicana: en diciembre de 1936 los billetes estampillados de los sublevados se cotizaban en Hendaya y San Juan de Luz a 50/1 en relación con los republicanos ${ }^{20}$. La posibilidad del tráfico ilegal de aquellos lo confirmaba una orden del 19 de noviembre de 1936 que consideraba "delito el contrabando de billetes como constitutivo del delito de auxilio a la rebelión".

Los hermanos Erviti Cilveti habrían colaborado en una red relacionada con el tráfico ilegal de billetes ilegalmente estampillados. El expediente de responsabilidades políticas del mayor de ellos, Pedro ${ }^{21}$, deriva de un sumario militar, el 13/1937, de la Auditoría de Guerra de la Coruña sustanciado contra él como miembro de una trama de la que también formaban muchas otras personas, la mayoría de ellas gallegas. En la sentencia de dicho consejo de guerra se decía "que existió una compleja organización criminal, fraguada en el extranjero, que se dedicó a estampillar billetes auténticos del Banco de España procedentes de los latrocinios y saqueos llevados a cabo en las distintas Sucursales que el mismo tenía en diversos lugares de la España Roja, así de billetes que estaban en circulación en la fecha de iniciación del Movimiento Nacional, como de otros que constituían las emisiones que la entidad bancaria de referencia tenía en reserva para sustituir a aquellos, valiéndose para el estampillado de troqueles falsos con los que se troquelaron multitud de billetes por valor de muchos millones de pesetas con el propósito de introducirlos en la España Nacional por medio de una numerosa banda de contrabandistas, españoles y extranjeros, que consiguieron poner en circulación una parte de aquellos". Aunque a Erviti se le ocuparon "billetes estampillados con el troquel ilegítimo", no pudo acreditarse su connivencia con la organización criminal de que se ha hecho mención ${ }^{22}$, por lo que tras dos años de cárcel sería absuelto con multa de 100.000 pesetas. De cualquier forma, la policía no dejó de señalar que desde el pueblo francés de Alduides, Ignacio y Evaristo Erviti Cilveti se habían "dedicado intensamente al paso de billetes con estampillado falso, de correspondencia para amigos y familiares residentes en esta región, a facilitar el paso por la frontera de personas que, temerosas de nuestra Justicia, buscaban refugio en Francia, así como a amparar las deserciones"23.

Los Erviti no fueron los únicos involucrados en esa actividad. Agustín Arrieta Martínez, otro importantísimo contrabandista afincado en Igantzi, también fue pro-

20 Sánchez Asiain, José Ángel, La financiación de la Guerra Civil española. Una aproximación histórica, Barcelona, Crítica, 2012, p. 186 y pp. 430-439.

21 ARGN, Audiencia Territorial de Navarra, Tribunal Regional de Responsabilidades Políticas de Navarra, Expedientes de Responsabilidades Políticas, Rollo 425.

22 Ibid.

23 Ibid. 
cesado por contrabando de billetes estampillados, aunque luego fuera absuelto por efecto de sus contactos políticos: una nieta suya estaba casada con Pelayo Moreno, importante abogado pamplonés y secretario general de Unión Navarra, partido sucursal de la CEDA. Nacido en 1859, Agustín Arrieta fue premiado con la Legión de Honor por las mulas y caballos suministradas al ejército francés en la Gran Guerra ${ }^{24}$. Por su parte, Pelayo Moreno era abogado habitual de los hermanos Erviti, figurando como tal en varios expedientes de contrabando incoados a estos o a sus subordinados, los hermanos Galarregui ${ }^{25}$.

\section{La desarticulación de la red de evasión organizada por Martín Erviti Cilveti en febrero de 1938}

E1 6 de febrero de 1938 la Policía desarticulaba una red de evasión de izquierdistas cuyo responsable máximo era Martín Erviti Cilveti, mencionado más arriba ${ }^{26}$. La operación no tuvo nada de casual, sino que fue el resultado de una estrategia diseñada desde la Delegación de Orden Público de Navarra, tal y como explicó en una memoria, presente en el mismo sumario, el titular de la misma, Pedro Llorente Miralles, que ocupó tal cargo desde finales de noviembre de 1937 hasta junio de 1938.

Pedro Llorente había combatido en los años diez y veinte en la guerra de Marruecos, siendo autor de la obra publicada en 1925 Organización de fuerzas coloniales. Con origen y familia en Navarra, fue "de los que salió el primer día del movimiento de aquí de Pamplona con sus requetés a reconquistar Guipúzcoa”, precediéndole "una sólida y envidiable reputación"27. Después de la toma de Irún fue nombrado responsable del Tercio de San Marcial, una unidad requeté encargada de la vigilancia directa de la frontera de Irún y Hondarribia y de las zonas colindantes de Navarra ${ }^{28}$. El Pensamiento Navarro de 4 de diciembre de 1937 se refirió a su experiencia marroquí de catorce años "como gran organizador de harkas y policía indígena" contra "tiranuelos y caciques". En ese artículo también se detallaba que, retirado por la ley Azaña, combatió a la República "con la pluma y con la palabra"; que el 18 de julio estaba en San Sebastián y tras el fracaso del Movimiento allí "logró milagrosamente escapar a Francia e inmediatamente llegó a Pamplona"; y que combatió en Oyarzun "mandando una compañía del Tercio de Montejurra".

En una Memoria integrada en el sumario, Pedro Llorente afirmaba declaraba su "profundo conocimiento" de la frontera guipuzcoana y navarra, "así como de todos los asuntos que relacionados con la misma se vienen desarrollando desde hace ocho años a la fecha", lo que le permitía retener en su "memoria un verdadero archivo de casos y nombres tanto de pasos por donde se ejercía y ejerce el contrabando como de personas dedicadas a estas actividades". Por ello, desde el momento en que asumió el cargo puso "especial cuidado" en todo lo relativo a la mencionada frontera, advirtiendo que pudo "desgraciadamente bien pronto comprobar que nada o muy poco se

\footnotetext{
24 ACMP, Sumarísimo 1365/1937; ARGN, Audiencia Territorial de Navarra, Tribunal Regional de Responsabilidades Políticas de Navarra, Expedientes de Responsabilidades Políticas, Rollo 412.

25 ARGN, Delegación de Hacienda de Navarra, Tribunal de Contrabando, 1935, 113; 1936, 32; $1936,41$.

26 ACMP, Sumarísimo de Urgencia 2364/1938.

$27 \quad$ Diario de Navarra de 2 de diciembre de 1937.

28 Archivo General de la Universidad de Navarra (AGUN), Fondos Personales, Fondo Lizarza, Caja 59, Unidades Especiales de Segunda Línea; El Pensamiento Navarro de 4 de diciembre de 1937
} 
había hecho sobre este particular cuando con la mayor seguridad para unos e impunidad para otros, se ejercía un escandaloso tránsito de la frontera perjudicial a todas luces para la Patria, siendo frecuente escuchar exclamaciones de las buenas gentes, de asombro y estupor por cuanto ya era público". Ante ello, puso en práctica "varias y simultáneas" medidas "recorriendo pueblos de la frontera de día y de noche, captando elementos que pudieran ser útiles, hasta conseguir establecer contactos y relaciones con personas que han sido y son mis colaboradores", medidas resultantes de "la práctica adquirida en los mandos de Policía Indígena y Harkas en Marruecos", con lo que pudo situar "emboscadas en montes y caminos que para el paso a Francia hubieran de recorrer quienes lo intentaren”. Además, combinó la investigación en los pueblos con la investigación en Pamplona, consiguiendo infiltrar a varios soldados en la red finalmente desarticulada.

Como conclusiones de la Memoria, Llorente decía "que nada o muy poco se había hecho" antes de él "para el descubrimiento de cuanto queda consignado" y "que dentro de Pamplona existen personas rojas que perseveran en su ideología y que no renuncian a sus actividades, de estas unas actuaban como ganchos de células más organizadas, que obrando a su vez con independencia y teniendo sus guías y conductos mecánicos, dependían de una más poderosa y bien organizada cabeza que radica en Francia (Españoles huídos) los cuales a su vez en íntima relación con los Frentes Populares Francés y Español, se hacen cargo de los reclutas que entregaban a la Guardia móvil francesa, quien a su vez por Port Bou, La Junquera y Puigcerdá los internaban en España". A su juicio, "todos los detenidos" eran "fusilables", e incluso alguno de ellos "con mayores cargos por sus antecedentes y actuación constante y otros por ser soldados que conscientemente se dedicaban a este negocio, por ideología y por sus estrechas relaciones con las cabezas directoras". Finalmente se insistía en la responsabilidad de Martín Erviti "que no necesitaba de dicho negocio".

En el sumario se relata cómo varios soldados fueron infiltrados en la red, fingiéndose desafectos en su visita a diversos bares pamploneses, la mayoría situados en el Casco Viejo, en los que se sospechaba que "existían algunas personas que se dedicaban a reclutar gente y proporcionarla medios para su evasión a Francia”.

Mediante la infiltración de los soldados se consiguió detener a varias personas que formaron parte de un intento de paso clandestino de frontera el 6 de febrero de 1938. Según las declaraciones de las personas detenidas, una camioneta conducía a los fugitivos desde Pamplona hasta las Ventas de Arraitz, donde dos guías les llevaban andando por el monte hacia Francia por Alduides en una marcha de varias horas.

Un informe, de fecha de 28 de febrero de 1938, procedente de la documentación incautada al Gobierno Vasco, que habría sido elaborado por alguno de los miembros baztaneses de la Red Álava (que veremos más adelante) que trabajaba en paralelo a la red de los Erviti y que se encuentra entre los fondos del Servicio Histórico Militar en Ávila ${ }^{29}$, comenta que aquella noche una ronda volante interceptó en Belate a 19 personas con tres guías, tiroteándolas y dispersándose el grupo. Tres personas murieron, otras dos habrían sido detenidas y el resto consiguió llegar a Francia. "También fue detenido el camión con su conductor y al día siguiente a estas detenciones, se

29 Archivo General Militar de Ávila (AGMAV), Servicio Histórico Militar, C.72,3,2 / 32, Información sobre situación militar fronteriza. Ese documento se menciona en Moreno Izquierdo, Rafael y Jiménez de Aberastur, Juan Carlos: Al servicio del extranjero. Historia del Servicio Vasco de Información (1936-1943), Madrid, Antonio Machado Libros, 2009, pp. 201-203, pero es interpretado equivocadamente como elaborado por la policía franquista. 
efectuaron otras sesenta, entre las que se encuentran varios guías pertenecientes a la organización izquierdista". En el mismo informe se distingue el funcionamiento de esa red de la de la Red nacionalista Álava. Mientras la primera pasaba a grupos numerosos desde Belate a Alduides, la segunda trabajaba con "lotes de un máximum de 3 a 4 personas". En el informe se indicaba que "durante esta última temporada ambas organizaciones han venido funcionando con relativa normalidad o, al menos, sin grave dificultad".

Según se desprende de las declaraciones de este sumario, y de otros que veremos después, habrían sido numerosas las expediciones organizadas por esta trama. El núcleo de la misma era Martín Erviti, que era quien negociaba las evasiones con los intermediarios. Como chóferes de las furgonetas que trasladaban a los fugitivos hasta Ventas de Arraitz figuran Faustino y Antonio Nuin Amorena, así como otras personas, ya involucradas en los expedientes incoados por la Delegación de Hacienda a la red de los Erviti por contrabando de reses. De todos ellos, en este, así como en otros sumarios al que también nos referiremos, se predica su afiliación política izquierdista. Como mugalaris que conducían a quienes deseaban marchar a Francia desde Ventas de Arraitz hasta Alduides a través del monte, se menciona a un vecino de un caserío cercano (Pedro Echenique) y a un vecino de Lantz (Martin Saralegui) a los que ya un año antes, el 18 de febrero de 1937, se les había incautado una partida de reses que conducían de Belate a Alduides y que eran ampliamente conocidos por los carabineros ${ }^{30}$.

En otras partes del sumario aparece subrayada la importancia de otros significados izquierdistas pamploneses como los socialistas Amador Aguirre Aranguren, José Ilundáin Arrarás y Pilar Ortega, que actuaban como personas de contacto con quienes querían fugarse. Otras personas también intervenían en Pamplona en la captación de fugitivos. Uno de ellos, el cenetista Eusebio Arbeloa Elcano, manifestó en cuanto al precio de la fuga, "que el precio de evasión es muy variable, desde cobrar cincuenta duros hasta hacerlo gratuitamente. Que el pago se efectúa en España pagando el que puede y en otro caso no paga, y a parte de esto por cada individuo que pasa a Francia los elementos del Frente Popular entregan determinada cantidad". Angel Pozas Tarrasó, ex afiliado de Izquierda Republicana, habría también desempeñado un papel importante porque el bar de su madre en la calle Jarauta había "sido centro donde se han verificado operaciones encaminadas al paso de hombres por la frontera".

Por efecto de este sumario, Martín Erviti fue condenado a ocho años. Muchos de la trama de Pamplona con antecedentes izquierdistas fueron castigados con penas de ocho o diez años. Por contra, los mugalaris que guiaban a los fugitivos a la frontera de los valles de Ultzama y de Baztán fueron absueltos. Con todo, en realidad ninguno pasó más de dos años en la cárcel, según se ve en el propio sumario.

No es la única noticia de la que disponemos acerca de esa red de evasión organizada por Martín Erviti. Los detalles de su funcionamiento vistos más arriba se confirman en otros sumarios, como el incoado en 1939 contra Germán Oyaga Gómez y Patrocinio Lasa Victoria ${ }^{31}$ o como el incoado contra José Ilundáin en marzo de $1942^{32}$, y en otros testimonios como el del ugetista de Caparroso Gerardo Guerra ${ }^{33}$ o

30 ARGN, Delegación de Hacienda de Navarra, Tribunal de Contrabando, 1937, 6.

31 ACMP, Sumarísimo de Urgencia 4129/1939.

32 ACMP, Sumarísimo ordinario 140/1942.

33 Guerra, Gerardo: Memorias de un campesino republicano. Caparroso 1936, Pamplona, Pamiela, 2012, pp. 119128 . 
el cenetista de Andosilla José Méndez Arbeloa ${ }^{34}$ que, tras estar muchos meses escondidos en su casa, se fugaron a Francia a través de aquélla.

La red de evasión de los Erviti tuvo ramales que fueron desarticulados con anterioridad. En el otoño de 1937 las autoridades pudieron desmontar otra red, dependiente de aquellos, en la que trabajaban dos vecinos de Irurita, Ambrosio Urrutia Michelena y su mujer, María Maz Alberro ${ }^{35}$. Este ramal operaba recogiendo a gente trasladada en autobús hasta el cruce de Berroeta, desde donde pasaban a Francia. En esta red operaban contrabandistas muy importantes, también de Irurita, como Benito Arraztoa Elizalde o como Tiburcio Michelena Echenique, y como el mencionado vecino de Lantz Martin Saralegui, todos insertos en la red de los Erviti. El Consejo de Guerra condenó a Maria Maz a 12 años de reclusión menor (luego reducida a dos años y medio) y a seis meses a su marido Ambrosio Urrutia. Por otra parte, el padre y un hermano de Maria Maz, Martín Maz Iceritegui y Joaquín Maz Alberro, ya habían ingresado en la Prisión Provincial de Pamplona el 24 y el 23 de julio de 1936 respectivamente, acusados, según testimonio de otro encarcelado, "de pasar republicanos a la nación vecina" 36 . Por ello, puede pensarse que la red de evasión funcionaría desde los primerísimos días.

\section{La red de Guillermo Frías Arizaleta}

Otra red de evasión importante fue la red organizada por el periodista republicano nacido en el valle de Baztán Guillermo Frías Arizaleta y que tenía como principal subordinado al funcionario Juan de Luis Osés. Los datos sobre la misma aparecen en dos consejos de guerra.

El primero de ellos, el 57634/1940, juzgado por el Tribunal Militar Territorial Primero de Madrid $^{37}$, integró a los procesados de dicha red organizada por Frías Arizaleta dentro de un sumario más global relativo a una red de evasión comunista que, extendida por diversas capitales de provincia, posibilitaba la fuga a Francia por Navarra. En total, serían juzgadas 80 personas de diferentes provincias. No obstante, en el mismo sumario se diferenciaría la red comunista, que habría comenzado a funcionar "en la primavera de 1938", de la de Frías, que habría empezado en diciembre de 1936, por lo que sería previa a aquella. Tras dictarse sentencia el 27 de octubre de 1940, el auto del Auditor de Guerra de 19 de noviembre de 1940 diría en relación con muchos de los procesados de Pamplona que carecían de "relación alguna, ni entonces ni ahora, con elementos comunistas e incluso separados por un gran lapso de tiempo" y estimaba que se desglosaran las actuaciones relativas a ellos en pieza aparte. En 26 de diciembre de 1941 se procedió a desglosar la pieza correspondiente a la Plaza de Pamplona, haciendo "un detenido estudio". Este segundo consejo de guerra realizado en Pamplona proporciona informaciones más concretas sobre la red de Frías $^{38}$.

\footnotetext{
Fondo Digitalizado Altaffaylla, Andosilla 30-33.

ACMP, Sumario 2150/1937.

Vierge, Galo: Los culpables. Pamplona 1936, Pamplona, Pamiela, 2006, pp. 87-91.

Archivo General e Histórico de Defensa (AGHD), Sumario 57634/1940, Cajas 3250/1, 3251/1, 3252/1, 3253/1 y 3254/1. La información sustancial está en la Caja 3250/1.

38 ACMP, Sumarísimo ordinario 189/42.
} 
Según el sumario, los mugalaris de la red de Guillermo Frías eran diversos vecinos del valle de Baztán. Los chóferes de la red eran los también baztaneses Pedro Adin y Aniceto Arocena. Mientras el responsable principal era Guillermo Frías, el secretario de la organización era Juan de Luis Osés. Por otra parte, como contactos con las personas que querían evadirse constan Serafín Úriz Turrillas, Pedro Urrizalqui Sarasate y Pilar Ortega Escudero, esta última ya mencionada en la red de los Erviti.

Guillermo Frías Arizaleta era un conocido periodista y republicano nacido en Elizondo en 1881. Tras trabajar en algunos países americanos, colaboró en diversos periódicos liberales e izquierdistas navarros y fue secretario del Partido Radical en Pamplona ${ }^{39}$. Por su parte, Juan de Luis Osés, el subordinado de Frías, que también habría colaborado con la red de Pilar Ortega Escudero y de Martin Erviti, era "empleado de la Excma. Diputación adscrito al Gobierno Civil” y había pertenecido al Partido Republicano Radical de Lerroux, llegando a ser secretario del mismo partido.

Quienes se evadían a través de esta red partían a Francia desde Lekaroz hacia la frontera francesa, la zona de la que eran originarios los hermanos Galarregui, afamados contrabandistas cómplices de los Erviti citados más arriba. En nuestro repaso de los expedientes de contrabando hemos localizado un caso en el que Frías actuó de intérprete en el juicio al que fueron sometidos varios contrabandistas baztaneses que trabajaban para los hermanos Erviti y para los hermanos Galarregui ${ }^{40}$.

La sentencia fechada de marzo de 1944 fue de sobreseimiento por "el espíritu que inspiran las recientes Disposiciones y Resoluciones del Gobierno en orden a la represión de las responsabilidades delictivas contraídas con ocasión de la pasada rebelión, y en consideración también a que la relevancia penal de los encartados no reviste gravedad suficiente".

\section{La Red Álava y sus antecedentes}

Paralelamente a las redes anteriores hubo también una red nacionalista, la denominada Red Álava por tomar el nombre del responsable máximo de la misma, el nacionalista alavés Luis Alava Sautu, que será el único que será ejecutado ante un pelotón de fusilamiento. Las características primordiales de dicha Red han sido reconstruidas por Juan Carlos Jiménez de Aberasturi y por otros autores ${ }^{41}$, afirmándose que empezó a funcionar a partir de agosto de 1937 por iniciativa del denominado Servicio Secreto Vasco o Servicio Interior, controlado enteramente por el PNV para mantener el contacto entre Bayona y la resistencia vasca. Desde entonces el paso de documentos y de personas a cargo de dicha red se habría hecho por Baztán gracias a un equipo formado por vecinos de dicho valle como Bittori Etxeberria, Agustín Ariztia,Timoteo Plaza y Felicitas Ariztia. No obstante, hay que precisar que, tal y como se verá, a partir de enero de 1938 Timoteo Plaza colaborará con la red desde Sara, tras su huída a Iparralde, y que Agustín Ariztia se fugará al mes siguiente.

39 García-Sanz Marcotegui, Ángel: Republicanos navarros, Pamiela, Pamplona, 1985, pp. 143-168.

40 ARGN, Delegación de Hacienda de Navarra, Tribunal de Contrabando, 1933, 103.

41 Jiménez de Aberasturi, Juan Carlos: "Los vascos en la II Guerra Mundial: de la derrota a la esperanza", Oihenart, 14 (1997), pp. 57-84; Moreno Izquierdo, Rafael y Jiménez de Aberasturi, Juan Carlos: Al servicio ... 
La memorialística y la historiografía han aceptado un relato basado en las declaraciones de miembros de esa red como Timoteo Plaza Mendiburu, su mujer Felicitas Ariztia Ibarra, su cuñado Agustín, y Bittori Etxeberria Agerrebere, que defiende su responsabilidad y participación exclusiva, y sin injerencias, en la gestión en la zona del Baztán de esa red del PNV y del Servicio Vasco de Información, datando su funcionamiento a partir del verano de 1937. Sin embargo, entre esa red y las anteriores existieron más puntos de conexión que los oficial u oficiosamente reconocidos $\mathrm{y}$, al igual que sucede con aquéllas, diversas circunstancias animan a plantear algunos interrogantes de calado acerca de su funcionamiento, uno de ellos la fecha de su puesta en marcha.

Como es sabido, la Red Álava será desmantelada en diciembre de 1940 a causa de la incautación en mayo del mismo año, por parte de los nazis, de la documentación que estos encontraron abandonada en la Delegación del Gobierno Vasco en París y que rápidamente entregaron a la Policía española. De esta manera, el 20 de diciembre de 1940 varios agentes de la Brigada Político-Social, desplazados desde Madrid, detienen a Bittori Echeverría y a Agustín Ariztia, así como poco después a la mayor parte de los miembros de la estructura ${ }^{42}$.

El sumario sobre dicha red, el 103590/1940, se conserva en el Archivo General e Histórico de Defensa ${ }^{43}$. Las informaciones sobre las que se basaron las investigaciones de la policía franquista están comprendidas en un denominado Informe sobre el Servicio Interior de 15 de marzo de 1939 elaborado por el propio servicio nacionalista y que estaba entre la documentación capturada por la Gestapo. En dicho Informe se dice que la Red efectuó 71 viajes de Francia a España y 69 viajes en sentido inverso, conduciendo 1242 documentos. La documentación transmitida contenía abundante información de carácter militar; sobre la estructura política del régimen franquista, incluso a nivel local; sobre cárceles y asesinados por los golpistas; sobre economía y abastecimientos; y sobre el espionaje alemán e italiano.

En aquel Informe sobre el Servicio Interior también constan informaciones relativas a la labor personal de los agentes de enlace, facilitándose datos sobre los enlaces navarros. Los enlaces baztaneses sobre los que se hablaba eran Bittori Etxeberria, Agustín Ariztia, Esteban Etxeberria y Felicitas Ariztia. Bittori Etxeberria Aguerrebere, que fue la persona a la que la policía identificó a la que la documentación aludía como Pepita Etxano, ocupaba, según aquel informe, "el primer puesto" de la red, fue "la primera incorporada a la labor", de ella "nació la organización" y "hoy sigue siendo la base absoluta de toda relación". Se mencionaba su papel en la génesis de la red. "Por sus manos" pasaba la totalidad de la documentación. Bittori Etxeberria fue la abertzale más significada en el valle de Baztán durante el periodo republicano: presidió Emakume Abertzale Batza desde noviembre de 1931 (La Voz de Navarra de 6 de ese mes) y en marzo de 1933 asumió la secretaria de la Junta Municipal del PNV, en una de cuyas vocalías estaba Agustin Ariztia ( La Voz de Navarra de 22 de ese mes). De este Agustín Ariztia, para la policía el Pablo Etxebeste de la documentación, se decía que tuvo que marchar a Francia "a resultas de sospechas de dedicarse a evasiones, creyéndole la policía complicado con elementos que trabajaban para el Socorro Rojo y que fueron capturados", habiendo realizado "innumerables servicios de enlace" y "salvado de la persecución allí y puesto en seguridad en Francia, a más

\footnotetext{
42 Jiménez de Aberasturi, Juan Carlos: "Los vascos en la...”, p.67.

43 AGHD, Sumario 103590/1940, Cajas 1929/4 y 1930/1.
} 
de 200 evadidos". Según el informe, Bittori Etxeberria habría sustituído a Agustín Ariztia, tras su marcha, por Gabriel Etxano, sobrenombre, según la policía, de Esteban Etxeberria Agerrebere, hermano de aquella, y que era "la reserva personificada, tiene mucha frialdad y criterio". Felicitas Ariztia, esposa de Timoteo Plaza, sería la Josefa Errazkin a la que aludían los documentos incautados y de la que se decía que solamente coordinaba la labor de las emakumes en sus labores asistenciales a presos. Sobre los demás navarros pertenecientes a la red, se daban datos del papel desempeñado desde Pamplona por Felipe Oñatevia Carmona, Modesto Urbiola Oroquieta y Rafael Goñi Latasa.

En otro documento que consta en el sumario titulado Diligencias tramitadas por la Comisaría de Estadística en relación con el descubrimiento de la red, además de incluir un informe con los resultados de las identificaciones, se decía que en el registro del domicilio de Bittori Etxeberria se encontró una nota conteniendo la dirección del recluso Aniceto Arocena Zubiría, uno de los chóferes de la red de Frías, lo que, aunque no fuera expresado por la policía, denotaría una cierta conexión entre ambas redes.

En su declaración, Bittori Etxeberria mencionó que estuvo desterrada en Pamplona con Felicitas Ariztia y otros en agosto y septiembre de 1936, fecha en que regresó a Elizondo, y que su trabajo dentro de la red, no era el de mugalari sino "aparte de establecer los contactos (...) el de garantizar y asegurar los enlaces y hacer que los correos llegaran con la mayor regularidad posible". También aseguró que Agustín Ariztia huyó a Francia en febrero de 1938 "por haber sido llamado por la Comandancia Militar y temer ser detenido", regresando a España en junio de 1939. Esto fue último fue corroborado por Felicitas Ariztia, quien añadió que estuvo confinado en Tours.

Agustín Ariztia dijo que recogía o dejaba correos en una borda entre Elizondo y Aldudes, actuando Bittori Etxeberria de receptora o de emisora. Según él, habría hecho esa labor entre octubre y diciembre de 1937 haciendo "tres o cuatro viajes". Reconoció que pasó al dirigente peneuvista alavés Javier Landáburu dejándolo en Aldudes después de recogerlo en el maletero de un coche en Elizondo. Sobre su marcha a Francia, fue ocasionada porque en febrero de 1938 (coincidiendo con la desarticulación de la red de los hermanos Erviti ${ }^{44}$ ) se presentó en su casa la Guardia Civil, citándole para comparecer en la Comandancia Militar y que, "asustado", huyó a Francia. En octubre del 38 fue confinado por los franceses en Tours donde estuvo hasta mayo del 39. En junio de 1939 se presentó a la Comandancia de Irún, donde le dijeron que se presentara a la Guardia Civil de Elizondo.

En unas segundas declaraciones de los tres de 31 de enero de 1941 Bittori Etxeberria añadió que no tuvo que sustituir a Agustín cuando este se fue porque un vascofrancés llamado Leoncio de Aldudes bajaba a Elizondo los domingos.

Por su parte, en las declaraciones de Esteban Etxeberria Agerrebere, este negó haber sido de la red y haber sido Gabriel Etxano.

Finalmente, el juez acabó el auto de instrucción el 10 de marzo de 1941. La sentencia de 3 de julio de 1941 dictó pena de muerte para 19 personas, entre ellas

44 En el informe más arriba mencionado de fecha de 28 de febrero de 1938, en el que se hablaba de la desarticulación de la red de los Erviti, se mencionaba que "uno de nuestros mejores agentes ha tenido que venir huido a Francia a causa de un favor que prestó en cierta ocasión a la citada organización de izquierdas", presumiblemente en referencia a Agustín Ariztia pues, aunque Timoteo Plaza también huyó algo antes, las declaraciones parece que se refieren a aquel. 
los baztaneses Bittori Etxeberria y su hermano Esteban y Agustín Ariztia, así como los vecinos de Pamplona Rafael Goñi, Felipe Oñatevia, Félix Ezcurdia y Modesto Urbiola. No obstante, tras la disconformidad mostrada por el auditor de guerra el 26 de julio de 1941, el Consejo Supremo de Justicia Militar revocó la sentencia el 19 de septiembre de 1942, limitando la pena de muerte a Luis Alava y castigando a los demás con penas de prisión de entre 20 y 30 años por considerar delito de espionaje y no de auxilio a la rebelión. Con todo, los tres encausados baztaneses pedirían en julio de 1946 el indulto acogiéndose al Decreto de 7 de octubre de 1945. Para entonces estaban ya en libertad vigilada. A principios de 1947 se emitieron los indultos para todos ellos.

De todo lo anterior se desprende que la policía solamente consiguió reconstruir la operatividad de la red a partir de agosto de 1937, fecha en la que Bittori Etxeberria se puso en contacto con los miembros del espionaje nacionalista en Baiona. Además, según consta en la investigación, Timoteo Plaza nunca fue considerado como miembro de la red, probablemente porque desde enero de 1938 y hasta después de la terminación del sumario estuvo residiendo en territorio francés. Bittori Etxeberria y Felicitas Ariztia nunca asumieron labores directas de paso de fronteras ni para personas ni para documentos. Dicha labor solamente fue reconocida por Agustín Ariztia, pero este solamente habría operado hasta febrero de 1938, momento este en que se fugó a Iparralde. Por lo tanto, según los datos del sumario, las labores de mugalari habrían sido implementadas por Agustín Ariztia durante el periodo mencionado o por el hermano de Bittori, Esteban Etxeberria, aún cuando ni este ni aquella reconocieron que lo hiciera.

Muchos otros extremos que hemos recabado matizan fuertemente esa versión del funcionamiento de la red Álava. Sobre todo, en relación con su puesta en marcha, en la medida en que habría funcionado como red de evasión desde los primeros momentos subsiguientes al golpe de estado de julio de 1936, pero también en relación con la circunstancia de que habría trabajado de la mano de las redes de contrabandistas tradicionales de la zona. Esto último refuta la tesis sostenida por la historiografía nacionalista de que dicha Red Álava era autosuficiente y de que se fundamentaba en el trabajo de aquellos tres o cuatro peneuvistas (incluyamos o no a Timoteo Plaza).

Acerca de esos aspectos nunca mencionados, hay que señalar, para empezar, el hecho objetivo del encarcelamiento simultáneo en la Prisión Provincial de Pamplona de Timoteo Plaza y de Fernando Inda Irigoyen el 7 de noviembre de 1936. Fernando Inda, afincado en el barrio de Gaztelu en Donamaria y hermano de la abuela del autor de este artículo, era uno de los contrabandistas más significados de la zona, operando a un segundo nivel a las órdenes de Agustín Arrieta, importante contrabandista citado más arriba, para quien trabajaba también su hermano Miguel Ignacio, afincado desde 1918 en un caserío del barrio de Frain en Lesaka. Aunque fueron liberados a los dos días, Timoteo Plaza donaría 2.000 pesetas a través de la Comandancia Militar el día 10 de noviembre de 1936, tal y como consta en la prensa. Pese a que no sabemos si el tema guarda relación con esa detención, recordaremos que Ignacio y Evaristo Erviti abandonaron su residencia en Elbetea y se establecieron en Alduides "a consecuencia de una aprensión llevada a cabo en el mes de Noviembre de 1936"45. Dicha detención simultánea hace presumir la existencia de una colaboración entre esas dos

45 ARGN, Expedientes de Responsabilidades Políticas, Rollo 425. 
personas de perfiles opuestos, uno contrabandista de ganado durante décadas y el otro militante notorio del PNV en Baztán, para la realización de pasos clandestinos de frontera ya desde el otoño de 1936. Sobre esa detención el propio Timoteo Plaza habló de forma confusa y con contradicciones, en la entrevista que concedió en 1978 al periodista Carlos Blasco y que se conserva en el Archivo Nacional de Euskadi. En dicha entrevista dicho nacionalista baztanés cuenta que "en octubre del 36 fue detenido pero sin ninguna acusación en concreto"46.

Con todo, mucho más interesante es otro sumario militar conservado en el Archivo de la Comandancia Militar de Pamplona ${ }^{47}$, hasta hace poco desconocido. Según dicho sumario, Timoteo Plaza habría colaborado plenamente a lo largo de 1937 con la red de los hermanos Erviti Cilveti en la cuestión de los billetes estampillados, huyendo a Francia en enero de 1938 por la proximidad de su detención al ser descubierta su participación. El sumario fue incoado contra el propio Plaza y contra un tal Angel Carbonell Ocáriz, avecindado en Elizondo, porque en noviembre de 1937 este último había llevado a Gijón 80.000 pesetas sin estampillar para cambiarlas por moneda de curso legal. Según hemos podido saber, Carbonell era hermano de un Comandante de infantería que luchó en el ejército franquista y en los años veinte era representante de automóviles en Pamplona, trasladándose a vivir al Baztán en los años treinta por ser su mujer maestra en dicho valle. Carbonell declaró que solía hacer viajes a Bilbao y a Gijón para blanquear billetes estampillados. También indicó que detrás de todo el asunto estaba uno de los hermanos Erviti, Evaristo, que, aunque estaba en Francia, se presentó un día en su garaje de Elizondo en septiembre-octubre de 1937. Según parece, según un oficio de la Comandancia Militar del Bidasoa en Irún, Carbonell había sido infiltrado en la red para desarticularla. El mismo Carbonell añadió que a causa de la "insistencia" de Plaza en proposiciones de "cambio de billetes", "le habló al Excmo. Señor General Martinez Anido, de que había unos cuantos señores que al parecer tenían sus idas y venidas a Francia, teniendo poco menos que un correo entre Plaza y otras personas que se trataba de descubrir en Francia es por lo que el declarante hizo la denuncia, sabiendo por algunas manifestaciones que debían tener una cantidad grandísima de billetes para cambiar en el caso de la toma de Madrid o de cualquier otra población". Asimismo, Carbonell declaró que Plaza le propuso el canje de billetes antes de la toma de Santander y que había hecho antes "algunos otros viajes" a Bilbao, siendo aquel "uno de los individuos que componían la Sociedad que se dedicaba al tráfico de billetes". No obstante, también comentó que "si este asunto se hubiera llevado mejor, y no hubiera trascendido a la calle, lo que les ha dado tiempo para prepararse, hubiera él podido descubrir toda la trama del asunto" ya que, aunque él hizo la denuncia "con el fin de que fuese confidencial y secreta, (...) fue desagradablemente sorprendido al ir sabiendo en la calle los acontecimientos que el declarante puso en conocimiento de la autoridad" por lo que "se ha perdido la labor que tanto tiempo ha costado para averiguar todas estas cosas; teniendo todavía esperanza de que puede hacerse con grandes cosas, si se siguieran las indicaciones que el declarante le dio al Excmo. Señor General Martinez Anido, y este a su vez al Señor Jefe de Fronteras". Equivocadamente Carbonell consideraba

46 Archivo Histórico de Euskadi (AHE), Fondo Carlos Blasco Imaz.

47 ACMN, Legajo 27, Orden XXX. Parte de la información de este sumario ha sido publicada en Ricardo Urrizola: Consejo de guerra. Injusticia militar en Navarra, 1936-1940, Tafalla, Txalaparta, 2017, pp. 234-235. No obstante, datos importantes del mismo han sido silenciados en dicha obra. 
que no creía que Plaza pudiera "facilitar noticias de nuestro campo a Francia" "pues ellos solo son gente metalizada y solo se dedicaban a asuntos de dinero". Por su parte, la Guardia Civil de Elizondo dijo que Carbonell tenía "frecuentes entrevistas" con Timoteo Plaza "a horas nocturnas" y que habían "hecho varios viajes a Pamplona y pueblos de la provincia" y a Vizcaya, Santander y Asturias. Se decía que Plaza y Evaristo Erviti estaban "en combinación" y que Plaza había sido multado hacía un año con 2000 pesetas por "contrabando".

En este mismo sumario se contienen también diversas informaciones que refieren la gran complejidad del asunto. Vicente Erramuzpe Michelena, el chófer que llevaba a Plaza y a Carbonell a Bilbao, Santander y Gijón, dijo haber sido testigo de que el último de ellos se entrevistaba en esas ciudades con importantes requetés pamploneses como Benito Santesteban y Generoso Huarte que habrían actuado como intermediarios. Santesteban había sido uno de los principales verdugos requetés en la retaguardia navarra ${ }^{48}$ y en el otoño de 1937 e invierno de 1938 era Jefe de Segunda Línea en Vizcaya. Huarte fue el primer responsable del Requeté navarro entre abril de 1931 y mediados de 1933, siendo detenido por ser el responsable de las decurias, una primera organización clandestina paramilitar de los tradicionalistas ${ }^{49}$. A finales de 1937 era el Inspector de todo el Norte en la Brigada de Policía del Cuartel General del General Solchaga. Obviamente ambos negaron cualquier contacto con Carbonell y con la red mencionada. Finalmente Carbonell fue condenado en mayo de 1938 a 14 años y 8 meses de cárcel y 800.000 pesetas de multa, pero finalmente la pena sería reducida a 2 años y seis meses, posiblemente porque en el recurso de la defensa se decía que "estaba encargado de una misión secreta" que era "un asunto de confianza del Ministerio de Orden Público".

La posibilidad de incriminar a destacados derechistas en aquellas actividades de contrabando de billetes penadas con severos castigos podría explicar que Timoteo Plaza se librara de cualquier castigo en un sumario militar que se le incoó a principios de enero de 1943 por la acusación de no haberse presentado al ser llamado su reemplazo, el de 1928. En ese sumario las autoridades franquistas baztanesas y la Guardia Civil declararon a favor de Timoteo Plaza, sin observar nada negativo en su estancia de varios años en el país vecino y afirmando su buena conducta mientras permaneció en España. En su declaración, Timoteo Plaza dijo que en los primeros meses se adhirió al Movimiento Nacional y que colaboró con él en "servicios de vigilancia y patrulla por los montes, carreteras y diversos edificios" y "que el día 1 ó 2 de enero de 1938, solo y clandestinamente atravesó la frontera, internándose en Francia", en donde había estado residiendo hasta entonces, trabajando en explotaciones agrícolas en el país vascofrancés y en las Landas francesas, sin enterarse de que había sido llamado su reemplazo a que pertenece a filas". Explicó su marcha de España "por tener una hermana Religiosa en Madrid, de la que carecía de noticias, y creyendo que desde la vecina Nación podría hacer algo por ella pasó a la misma". Añadió que no había pertenecido a ningún partido ni sindicato y que había regresado a España para "normalizar su vida particular". Se decretó contra él la prisión atenuada, debiendo de presentarse cada quince días en el puesto de la Guardia Civil de Elizondo. En julio

48 Mikelarena, Fernando, Sin Piedad. Limpieza politica en Navarra 1936. Responsables, colaboradores y ejecutores, Pamplona, Pamiela, 2015, pp. 269-284.

49 Lizarza Iribarren, Antonio: Memorias de la Conspiración, Pamplona, Editorial Gómez, 2a ed., 1953, pp. 16-17 y 23; Del Burgo Torres, Jaime: Conspiración y Guerra Civil, Madrid, Alfaguara, 1979, pp. 510-515. 
de 1943 el auditor de guerra dijo que, aunque a Plaza le correspondía en principio el "correctivo de cuatro años de recargo en el servicio", al estar la falta comprendida en el indulto de Franco de 28 de septiembre de 1939, se le indultaba de aquella pena ${ }^{50}$.

Sorprende que el sumario no se saldara con más consecuencias cuando Plaza había sido objeto de investigación en el sumario anteriormente citado junto con Carbonell y cuando su mujer, Felicitas Ariztia, había estado procesada en el sumario de la Red Álava y habría sido fácil colegir por parte de la policía, por mera lógica, que el propio Plaza habría estado involucrado en la misma, al igual que su cuñado Agustín Ariztia y que Bittori Etxeberria, otra persona de su círculo íntimo de confianza. Además, Timoteo Plaza había colaborado estrechamente con Pepe Mitxelena, significado miembro del Servicio Vasco, con quien había estado en Dax durante dos años y medio ${ }^{51}$.

Por otra parte, Timoteo Plaza proporcionó una versión muy diferente de su huida de las versiones proporcionadas en los párrafos anteriores en la ya mencionada entrevista que le realizó Carlos Blasco. Contó que hasta finales de 1937 dispuso de la protección del responsable de un teniente de carabineros que estaba de comandante en Elizondo: "Me dijo que mientras él estuviera allí a mí no me pasaría nada y si por cualquier cosa él no pudiera hacer nada ya me avisaría. Por lo tanto hasta finales del 37 estuve tranquilo. A finales del 37, me avisó que le habían trasladado a San Sebastián y por lo tanto yo no podía ya tener su protección”. Según él, tras la marcha de dicho teniente, Timoteo Plaza cruzó la frontera por el monte porque fueron a detenerle.

Timoteo Plaza reconoció en aquella entrevista que se dedicó a pasar gente entre julio de 1936 y enero de 1938 y que la Red Alava “empezó en el año 38 y desapareció en el 41", pero que "ya habíamos estado pasando de aquí a Francia y de Francia aquí durante unos años". De esta forma, especificó que "en el 36 empezamos a pasar y a ayudar a gente. Me fui en el 38 y volví en el 42" y que "nos ocupábamos de los presos e intentábamos pasarlos al otro lado. Por aquí pasó mucha gente. Además ni les preguntábamos cómo se llamaban ni de qué partido eran. Nosotros hemos ayudado todo lo que hemos podido. Es lo que estuve haciendo antes de marcharme".

En el reportaje que Eugenio Ibarzábal escribió sobre la Red Álava también se decía que antes de que Bittori Etxeberria se pusiera en contacto en agosto de 1937 con José María Lasarte para crear la Red Álava, ya "en compañía de un grupo de baztaneses, se había destacado por ayudar a cruzar la frontera a las personas que hallándose en situación comprometida así lo solicitaban. Si en un primer momento los beneficiados serían antifascistas navarros, especialmente de la Ribera, más tarde, conforme avanzaban las tropas, las llamadas de socorro llegaban del resto de las regiones del País, convirtiéndose el Baztán en al esperanza de muchos demócratas perseguidos por el franquismo" 52 . La misma Bittori Etxeberria habló en otra entrevista en términos parecidos, añadiendo que "a veces acudíamos a los contrabandistas que les pagábamos de nuestro bolsillo. Jamás se pedía la afiliación o nombres, venían mandados a través de gentes que conocían nuestra labor. Gentes muchas veces importantes" 53 .

\footnotetext{
ACMP, Sumario 837/1943.
}

AHE, Fondo Carlos Blasco Imaz.

52 Ibarzábal, Eugenio: 50 años de nacionalismo vasco, 1928-1978, San Sebastián, Ediciones Vascas, 1978, pp. 227-228.

53 Altaffaylla: Navarra 1936. De la esperanza al terror, Tafalla, Altaffaylla, 2003, pp. 156-157. Por contra, en las entrevistas que Txueka Inchusta ("Erregimen frankistaren aurkako zenbait ekintza eta erakunderen berri”, $\mathrm{Ge}$ - 
La mucho más conocida Red Álava, que funcionó desde 1938 a 1941, habría tenido, por consiguiente, como precursora una red previa a cuyo mando estaba Timoteo Plaza antes de 1938 porque esta "ya estaba organizada. Ya habíamos pasado de aquí a Francia y de Francia a aquí durante unos años".

Se ha dicho que a través de esta red nacionalista baztanesa pasaron a Francia hasta las detenciones de diciembre de 1940 personalidades del PNV como Javier Landaburu, el alcalde de Oyarzun Beldarrain, Teófilo Lecároz, Pello Irujo, José Mandaluniz, Jesús Insausti, y que, en total conseguirían fugarse "cerca de 200 personas", muchas de ellas no nacionalistas ${ }^{54}$.

Por otra parte, dos nacionalistas irundarras, Pepe Michelena y Ramón Agesta, trasladados a Iparralde desde la caída de Irún y estrechos colaboradores de José María Lasarte en las labores precursoras de lo que sería el Servicio Vasco de Información, desde octubre del 36, además de otros cometidos, también llevarán a cabo, junto con Timoteo Plaza, "muchos pasos terrestres por la zona fronteriza de SaraLarrun" en colaboración con el contrabandista de la localidad vascofrancesa de Sara Paul Dutournier ${ }^{55}$.

En cuanto a la forma de proceder de esta red, según el informe que hemos citado más arriba de 28 de febrero de 1938, confeccionado por el propio Servicio Vasco de Información, esta red nacionalista pasaría a gente en grupos de tres personas como máximo y con un número muy restringido de guías, cualidad esta última que no era privativa porque también caracterizaba a la otra.

\section{A modo de conclusión}

Tal y como se ve en los casos de Galicia y Cataluña mencionados en la bibliografía citada a principio del artículo, también en el caso navarro se advierten dificultades a la hora de analizar un tema como el de las redes de evasión, y de la colaboración en ellas de las redes tradicionales de contrabando, en el contexto de la guerra civil a causa del interés de los implicados por borrar cualquier huella de su actuación y a causa de los sesgos intrínsecos de los informes policiales y militares incorporados a los sumarios que sirven de base al análisis y que, de cualquier forma, permitirían sólo una cierta aproximación al fenómeno. Otro factor es el hecho, corroborado en Galicia y en Navarra, de la incidencia en la actividad referida de nuevos personajes que, aprovechando sus redes de influencia o su posición en la jerarquía administrativa del nuevo régimen, entran en la misma, acompañando la acción de los organizadores de estas tramas.

Del repaso realizado a las tres redes de evasión reconstruídas, se infiere el importante papel de los contrabandistas de ganado en ellas, no sólo en el caso de la red de los hermanos Erviti que llevaban años en esa actividad, habiendo desarrollado connivencias vitales en el entorno. Serían los Erviti quienes, en función de sus intereses, a demanda del gobierno republicano, accedieron a ponerla en funcionamiento mediante sus medios y contactos.

rónimo de Uztáriz, 4 (1990), p. 113) realizó a Timoteo Plaza, a su mujer, Felicitas Ariztia, y a Modesto Urbiola hay más inconcreciones.

54 Altaffaylla: Navarra 1936 ..., p. 157; Moreno Izquierdo, Rafael y Jiménez de Aberasturi, Juan Carlos: Al servicio., p. 120.

55 Moreno Izquierdo, Rafael y Jiménez de Aberasturi, Juan Carlos: Al servicio ..., pp. 43-48. 
En el caso de la Red Álava, no es en absoluto creíble que una red organizada por el PNV de la zona pudiera desenvolverse a la altura de la anterior de forma autónoma. Ya hemos visto que diversos datos avalan la confluencia de la red de los Erviti con la red nacionalista que precedió a la Red Álava desde el otoño de 1936 y con la Red Álava mismo entre agosto de 1937 y febrero de 1938. Sin su actividad colaborativa es imposible de imaginar que Timoteo Plaza, su cuñado Agustín o la misma Bittori Etxeberria hubieran podido manejarse por los montes baztaneses, un espacio en el que la gente de los caseríos, la mayoría de ellos campesinos arrendatarios, estaba muy volcada en aquellas redes de contrabando de ganado.

Por lo tanto, en Navarra la evasión de los opuestos al franquismo se canalizó sobre todo a través de una red preexistente de contrabandistas de ganado. Quienes se mostraron interesados en la conformación de una vía estable por la que personas contrarias a los sublevados en julio de 36 quisieran trasladarse a Francia desecharon la opción de articular redes propias y optaron por otras existentes de antemano. En esa elección pudo influir el reconocimiento de que se carecía de posibilidades para conformar una alternativa compuesta de chóferes y mugalaris a partir de militantes propios únicamente dedicados a esa actividad, ya que para ello harían falta, como mínimo, individuos que conocieran bien el terreno, que fueran capaces de esquivar a las fuerzas policiales y que, además, pudieran contar con la complicidad del entorno. Esto último es importante porque los vecinos de los caseríos próximos a los caminos por los que transitaba la red eran susceptibles de ser comprados, chantajeados o coaccionados por las fuerzas militares, carabineros y guardias civiles que vigilaban la zona para convertirse en confidentes y había que asegurar, por las vías que fuera, que esa colaboración con dichos contingentes no se concretara, lo que estaba exclusivamente en la mano de aquellas redes de contrabandistas, pero estaba absolutamente vetado a personas externas a ellas. Por último, los contrabandistas de ganado pudieron esgrimir sus relaciones con sectores republicanos y nacionalistas.

Por otro lado, es tremendamente llamativo que las tres redes (la de los hermanos Erviti, la red de los nacionalistas baztaneses y la red de Guillermo Frías) se desenvolvieran a lo largo de casi dos años, entre julio de 1936 y febrero de 1938, con una gran impunidad y que la primera, y más importante de ellas, la de los hermanos Erviti, sólo fuera cercenada con la llegada de Pedro Llorente Miralles a la Delegación de Orden Público en noviembre de 1937. También resulta curiosa la relativa levedad de los castigos inferidos a los componentes de la red en torno a los Erviti, nada que ver con la mencionada recomendación de fusilamiento de los mismos que hacia en su informe Pedro Llorente, y el hecho de que Timoteo Plaza pudiera volver a Lekaroz sin problemas en 1943, habiendo contado con la protección del responsable de los carabineros hasta enero de 1938. De cualquier forma, para mayor complejidad, tampoco hay que olvidar que una tercera red, la de Frías Arizaleta, también se ubicó en el mismo entorno que la de Plaza y Ariztia, pudiéndose pensar que se superponía con ella y también con la de los Erviti cuando esta utilizaba los senderos de la zona occidental del valle de Baztán.

Puede pensarse que el funcionamiento de estas redes contó con algún tipo de connivencia con las nuevas autoridades, al menos a escala provincial. Es preciso recordar que los encargados de la vigilancia de la frontera en los valles en los que transcurre la acción entre julio de 1936 y febrero de 1938 fueron, sobre todo, voluntarios carlistas y falangistas destacados con sus unidades en el monte y dependientes de aquellas autoridades provinciales. Llegados para reforzar la vigilancia de la 
muga, el número de esos voluntarios era muchísimo mayor que el de los carabineros y guardias civiles destinados en los cuarteles de la zona, a causa de que muchos de los miembros de la primera de las dos fuerzas policiales mencionadas habían desertado en julio de 1936 y se pasaron al ejército republicano. En este sentido, tal y como indicaban los informes de la misma Red Álava que se conservan en Ávila, así como Ezkieta Yaben ${ }^{56}$, las fuerzas del Tercio de Roncesvalles, primero, y las fuerzas militares después que le sucedieron a partir de principios de 1938, destinadas en la frontera desde julio de 1936 para la vigilancia de la misma, representaban contingentes de varios cientos de soldados, voluntarios o de reemplazo, a los que se les sumaban fuerzas policiales. Con todo, resulta evidente que, por la facilidad con que llevaban a cabo los pasos clandestinos de frontera los miembros de la red mencionada, los empeños de impermeabilización de la frontera de los milicianos carlistas y falangistas, no fueron en absoluto fructíferos, de forma que los mugalaris de la zona salvaron sin demasiadas complicaciones los obstáculos.

Ya hemos visto que los hermanos Erviti Cilveti no le hicieron ascos a desarrollar actividades clandestinas de tráfico de armas, y seguramente también de documentos y de divisas, a través de la frontera en favor de los sectores golpistas. Su comportamiento estaba guiado estratégicamente por la asunción del principio de que su propia supervivencia en el futuro en un negocio como el del contrabando estaba condicionado a la cooperación de dichas autoridades. Sus pasos se relacionan de alguna manera con la teoría del don generoso de Bourdieu según la cual "el don que no es restituido puede convertirse en una deuda, una obligación duradera", pudiendo ser una forma de tipo moral "de retener a alguien duraderamente" tan efectiva como "las obligaciones abiertamente económicas que impone el usurero" 57.

A las obligaciones instigadas por un primer don generoso (en el caso que nos ocupa, el tráfico de armas y de documentos en los meses previos a julio de 1936, y seguramente también con anterioridad) se sumarían otras surgidas de la más que posible coparticipación en el negocio de los billetes estampillados. Por más que este estuviera severamente castigado por la jurisdicción militar, no cabe duda de que la enorme facilidad de su práctica y las expectativas de un rápido y cuantioso enriquecimiento pudieron prevalecer ante cualquier sensación de estar arriesgando excesivamente. También es posible que los carlistas estuvieran interesados a nivel organizativo en ese negocio con el fin de obtener fondos para el sostenimiento de estructuras propias, siendo un indicio de ello la mención que se hacía en el sumario militar incoado a Carbonell y a Plaza, de la colaboración activa en el mismo de requetés importantes como Benito Santesteban y Generoso Huarte. Además, dicha cooperación pudo provocar que las nuevas autoridades provinciales pudieran ser objeto de chantaje por el uso que sus socios contrabandistas pudieran hacer de la información confidencial relativa a aquélla.

Por otra parte, a pesar de que el descubrimiento de la colaboración con el paso clandestino de izquierdistas a Francia podía ser, en teoría, duramente castigado, siendo catalogado como de delito de adhesión a la rebelión, por otra parte, también era un negocio de relativa baja exposición. Los varios cientos de pesetas que cada huido podía abonar a la red podían convertirse en una cantidad cuantiosa a partir de ciertos

56 AGMAV, Servicio Histórico Militar, C.72,3,2 / 32; Ezkieta Yaben, Fermín: Los fugados del Fuerte San Cristóbal, 1938, Pamplona, Pamiela, 2003, pp. 156-160.

57 Bourdieu, Pierre: El sentido práctico, Madrid, Taurus, 1991, p. 212. 
niveles de tráfico. Y los participantes contaban con el blindaje que les proporcionaba el interés de las autoridades en que las hipotéticas responsabilidades penales por el paso clandestino de personas o por el tráfico de billetes estampillados no subieran hacia arriba en la pirámide del poder provincial.

Además de la posible participación de significados carlistas navarros en la red de blanqueo de billetes estampillados reseñada en el citado sumario incoado a Angel Carbonell y Timoteo Plaza, lo que acreditaría la participación activa de miembros de las nuevas autoridades provinciales en esas redes, hay que considerar diversas circunstancias en relación con aquel posible blindaje.

Recordemos que Pedro Llorente, el Delegado de Orden Público que desarticuló la red de los Erviti y que, a fin de cuentas, era una autoridad llegada de fuera e impuesta desde el Gobierno de Salamanca, se quejó abiertamente, como vimos, del rumor generalizado sobre el funcionamiento de la misma y de la inexistencia de acciones contra ella. Seguramente su petición de duro castigo habría sido atemperada por los carlistas y falangistas navarros y podría haber motivado su marcha de Navarra en junio de 1938.

Tras la durisima limpieza política llevada a cabo en Navarra entre julio de 1936 y abril de 1937 que se saldó con el asesinato de casi tres mil navarros o residentes en Navarra, la inmensa mayoría de partidos de izquierda ${ }^{58}$, es posible que las autoridades provinciales surgidas del golpe de estado se posicionaran, tras aquellos meses calientes, a favor de comerciar y sacar provecho de la huída de desafectos, actitud de la que eran sabedores los organizadores de la red. Sin duda alguna, este tráfico alimentó un negocio del que algunos miembros de la nueva élite pudieron extraer grandes beneficios económicos.

De cualquier forma, si, como dijimos a principios de este párrafo, no hemos encontrado a ningún miembro de la nueva élite política provincial procesada por estos hechos, esa circunstancia también está ocasionada porque los tribunales militares optaron por limitar el radio de sus investigaciones a los involucrados directamente en la red y no extenderlo a la órbita de los poderes locales que desde los mismos valles o desde Pamplona actuaban de forma permisiva o connivente.

Otro factor que es preciso retener es el hecho de que el momento histórico en el que se enmarcan los hechos era un momento de gran incertidumbre. Nadie sabía lo que podía ocurrir en el corto y medio plazo. Por ello, las nuevas autoridades navarras se habrían preocupado por mantener hilos abiertos con redes subterráneas de contrabando que podían acudir en su auxilio en un futuro próximo en un juego de dobles juegos por doquier. Y, como es sabido, cualquier estrategia inteligente pasa obligadamente por incluir en el diseño de la misma posibles vías de salida al menor coste posible.

58 Manejamos la cifra de 2.857 contabilizados en Altaffaylla, Navarra 1936 ..., p. 721. 